\title{
THE USE OF RADIATION THERAPY IN THE SYMPTOMATIC TREATMENT OF OSTEOARTHRITIS OF THE KNEE
}

\section{T.V. Udatova', V.V. Protsenko ${ }^{2}$}

${ }^{1} X$-ray radiology department, Feofania Hospital No 1,

${ }^{2}$ Institute of Traumatology and Orthopedics of the NAMS of Ukraine, Kiev, Ukraine

\section{INTRODUCTION}

Osteoarthritis affects over $20 \%$ of the world's population. The prevalence of osteoarthritis in patients over 35 years old reaches $50 \%$, while in patients over 55 years old reaches $80 \%$ [1]. Deforming osteoarthritis is the cause of chronic pain in $45 \%$ of the population of economically developed countries of the world $[4,5]$. In the treatment of osteoarthritis, non-steroidal anti-inflammatory drugs, aimed at relieving pain, and cartilage repair have become widespread [2, 3, 7]. Physiotherapy is often used to treat inflammatory changes in the joint. All of the above methods of treatment are included in modern standards for the treatment of osteoarthritis, but in some cases they are not effective enough, which leads to the search for alternative methods. The latter includes orthovoltage radiotherapy, which is prescribed in cases of ineffectiveness of standard treatments for osteoarthrosis [6]. Orthovoltage radiotherapy is an effective treatment for osteoarthrosis, pain reduction occurs in 65-90\% of patients, and minimal doses of X-ray radiation used to treat osteoarthrosis do not cause tissue damage [6].

\section{MATERIALS AND METHODS}

Treatment with orthotovoltage radiotherapy was performed in 39 patients with deforming osteoarthritis of the knee joint. X-ray stage III was determined in $29(74,4 \%)$ patients, and X-ray stage II - in 10 (25,6\%). The course of orthotovoltage roentgenotherapy was performed on a radiotherapy device "RUM-17". Irradiation at a voltage of $200 \mathrm{kV}$, a current of $10 \mathrm{~mA}$, a layer of half attenuation of 1,7 $\mathrm{Cu}$, a filter of $1,0 \mathrm{~mm} \mathrm{Cu}$ and $1,0 \mathrm{~cm} \mathrm{AI}$ and a focal length of $46 \mathrm{~cm}$ with an interval of 48 hours. Single doses were 0,50-1,0 Gray, total 5,0 Gray. The severity of pain in osteoarthritis of the knee joint was assessed according to the VAS scale (Visual Analog scale), in mm on a 100-mm scale (no pain - 0, maximum pain syndrome - 100), WOMAC scale (Western Ontario and McMaster rate arthrose index), mm and the Lequesne index (in points).

\section{RESULTS}

When assessing the effectiveness of orthovoltage radiotherapy, it was established that there is a decrease
Article history:

Received 26 February2019

Received in revised form 17 March 2019

Accepted 2 April 2019

in the level of pain syndrome measured on a VAS scale at rest, the WOMAC and the Lequesne index throughout the entire observation period. The level of VAS scale at rest and WOMAC did not exceed $20 \mathrm{~mm}$ 3 years after treatment, and after 5 years did not exceed $10 \mathrm{~mm}$. There was also a decrease in the time of pain from 15 minutes to 3,5 minutes. The range of motion in the knee joint increased to $80 \%$ by the end of 3 years of observation. The values of the Lequesne index decreased from 14 to 5 points 3 years after treatment.

\section{CONCLUSIONS}

1. o-voltage low-dose radiotherapy is a clinically more effective, compared with the standard, treatment of osteoarthritis.

2. Long-lasting and more pronounced analgesic effect gives grounds to recommend orthovoltage radiotherapy as the method of choice in the treatment of osteoarthritis.

\section{REFERENCES}

1. A meta-analysis of randomized researchers during 1966-2003. / J. Bjordal, R. Thorsen, S. Vondrak [et al.] // Rheum. - 2005. - Vol.18, No 6. - P. 315-328.

2. Effect of oral chondroitin sulfate on the progression of knee osteoarthritis: a pilot study. / D. Uelelhardt, E. Thonar, P.D. Delmas [et al.] // Osteoarthr. Cart. 2006. - No 6. - P. 49-56.

3. Efficacy and safety of valdecoxib in treating the signs and symptoms of rheumatoid arthritis: a randomized, controlled comparison with placebo and naproxen / W. Bensen, A.Weaver, L. Espinoza [et al.] // Rheumatology - 2002. - Vol. 41. - P. 1008-1016.

4. Estimates of the prevalence of arthritis and other rheumatic conditions in the United States. Part I. / C.G. Helmick, D.T. Felson, R.C. Lawrence [et al.] // Arth. Rheum., - 2008. - Vol. 58. - P. 15-25.

5. Gender variations in clinical pain experience / $M$ Unruch // Pain. - 1996. - Vol. 2 - P. 123-161.

6. GLATzEL M. Analgesic radiotherapy for osteoarthrosis of digital joints and rhizarthrosis./ M.Glatzel, D.Frohlich, S. Basecke // Radiotherapy and Oncology - 2004. - Vol. 71. - P. 24.

7. GLegG D.O. Celecoxib in the treatment of the painful osteoarthritis of knee / D.O. Glegg, D.S. Reda, M. Abdellatif / / Arthritis Rheumatol. - 2007. - Vol. 42, No 11. - P. 2325-2329. 